\title{
PENGETAHUAN DAN SIKAP IBU TENTANG KONTRASEPSI SUNTIK DI RB SITIANA BARUS DESA NAMO BINTANG KEC.PANCUR BATU TAHUN 2015
}

\author{
Yufdel*, Dina Indarsita*, Hanna Lalia Br Ginting** \\ * Staf Dosen Poltekkes Kemenkes Jurusan Keperawatan Poltekkes Medan \\ ** Mahasiswa Poltekkes Kemenkes Jurusan Keperawatan Poltekkes Medan
}

\begin{abstract}
Injection contraception is one of effective contraception method in which a method in its using has effectiveness or a higher survive and the lower rate of failure than the natural contraception. The objective of this research is to study knowledge and behavior of mothers about injection contraception at RB Sitiana Barus desa Namo Bintang subdistrict of Pancur Batu of 2015. This research applied descriptive study in order to depict the actual condition of knowledge and behavior of mother about injection contraception at RB Sitiana Barus desa Namo Bintang subdistrict of Pancur Batu of 2015. This research was conducted with the sample of 31 respondent by cross sectional design. The data was collected by questionnaire that consist of knowledge and behavior. Based on the result of research indicates that the knowledge of mother about injection contraception of 31 respondent with sufficient knowledge is 13 respondent (41.9\%) and have the positive behavior for 30 respondent (96.8\%). It is suggested to the medician in RB Setiana Barus to increase the health service.
\end{abstract}

Keywords : Knowledge, Behavior, Contraception

\section{PENDAHULUAN}

Pengetahuan Masyarakat yang baik terhadap Kontrasepsi membuka kemungkinan meningkatnya minat dan kepercayaan masyarakat untuk melakukan program KB (BKKBN, 2008 dalam Aga Bramantia, 2013).

Pengetahuan atau kognitif merupakan domain yang sangat penting dalam membentuk tindakan seseorang (overt behavior). Dalam menentukan sikap, pengetahuan, pikiran, dan keyakinan memegang peranan penting (Notoatmodjo, 2007; dalam Dwi mardiantari, 2011).

Menurut Notoatmodjo (2007; dalam Dwi mardiantari, 2011) menjelaskan bahwa sikap mempunyai beberapa komponen yaitu, kepercayaan (keyakinan), ide, dan konsep terhadap suatu objek, kehidupan emosional, atau evaluasi terhadap suatu objek dan yang terakhir kecenderungan untuk bertindak (trend to behave). Beberapa komponen diatas secara bersama-sama membentuk sikap yang utuh (total attitude).

Kontrasepsi suntik merupakan metode kontrasepsi efektif yaitu metode yang dalam penggunaannya mempunyai efektifitas atau tingkat kelangsungan pemakaian relatif lebih tinggi serta angka kegagalan relatif lebih rendah bila dibandingkan dengan alat kontrasepsi alami (BKKBN, 2007: dalam Dwi Mardiantari, 2011).

Penggunaan kontrasepsi pada pasangan usia subur di Indonesia meningkat pada tahun 2009-2010. Yang paling meningkat adalah penggunaan alat kontrasepsi injeksi/suntik. Kontrasepsi suntik merupakan metode kontrasepsi yang diberikan melalui suntikan. Metode suntikan telah menjadi bagian gerakan Keluarga Berencana Nasional serta peminatnya semakin bertambah. Tingginya peminat suntikan karena Kontrasepsi suntik aman, sederhana, efektif, tidak menimbulkan gangguan dan dapat dipakai pasca persalinan (Manuaba, 2003; Dwi mardiantari, 2011).

Dengan meningkatnya jumlah penduduk Indonesia dari tahun 2010 yang berjumlah 237.641.326 jiwa, kemudian pada tahun 2014 mengalami peningkatan 244.814.9 jiwa. (Badan Pusat Statistik, Ari Wahyudi 2015).

Berbagai upaya dilakukan untuk mengendalikan laju pertumbuhan penduduk, termasuk didalamnya adalah program Safe Mother Hood yang meliputi Keluarga Berencana untuk mencegah kehamilan, pelayanan antenatal, persalinan yang aman, pelayanan obstetric esensial (BKKBN, 2008 dalam BKKBN 2011).

Data WHO menunjukkan bahwa pengguna alat kontrasepsi Implant di seluruh dunia masih di bawah alat kontrasepsi suntik, pil, kondom dan IUD, terutama di negara-negara berkembang. Persentase penggunaan alat kontrasepsi suntik yaitu 35,3\%, pil 30,5\%, IUD 15,2\%, sedangkan Implant dibawah $10 \%$ yaitu $7,3 \%$, dan alat kontrasepsi lainnya sebesar $11,7 \%$. Pada saat ini diperkirakan memakai IUD/AKDR, 30\% terdapat di CINA, 13\% di Eropa, 5\% di Amerika Serikat, 6,7\% di negara-negara berkemabang lainnya (Safrina, 2012 dalam Nella destari 2014). 
Persentase akseptor kontrasepsi Aktif menurut metode kontrasepsi di Indonesia IUD 11,03\%, MOW $3,53 \%$, MOP $0,68 \%$, Implan 8,26\%, Kondom 2,50\%, Suntik 47,19\%, Pil 26,81\% (Kemenkes RI, 2013 dalam Nella destari 2014).

Di Propinsi Sumatera Utara, perkembangan pasangan usia subur yang aktif sebagai peserta kontrasepsi yang dilaporkan dari kabupaten/kota sampai akhir Desember 2012 mencapai 1.312 .405 pasangan atau $65.19 \%$ dari 2.013.452 pasangan usia subur yang ada di Sumatera Utara. Persentase PIL 35,24\%, suntikan 33,53\%, IUD 10,63\%, MOW 8,34\%, Implant 7,41\%, Kondom $4,58 \%$ dan dengan metode medis operasi pria (MOP) hanya $0,28 \%$ dari jumlah pasangan usia subur yang aktif sebagai peserta KB (Wiratno, 2012 dalam Nella destari 2014).

Jumlah PUS di Kabupaten Deli Serdang sampai tahun 2013 sebanyak 300.133 jiwa, dengan capaian Akseptor KB baru sebesar 14,98\%, peserta KB aktif sebesar 73.06\%. Akseptor yang menggunakan MKJP seperti: IUD sebesar $11,11 \%$, MOP/MOW sebesar 5,74\%, implant sebesar $8,035 \%$. Non MKJP yaitu memakai kondom sebesar $8,23 \%$, suntik sebesar $31,45 \%$ dan pil sebesar 35,41\% (Yanti, 2013 dalam Nella destari 2014).

Jumlah PUS di Kecamatan pancur batu sampai tahun 2014 sebanyak 15.503. Akseptor yang menggunakan IUD sebesar 1.881 jiwa, MOP sebesar 91, MOW sebesar 665, Kondom sebesar 681, Implant sebesar 108, Suntik sebesar 3.538, dan Pil sebesar 3.270 (Data Kecamatan Pancur Batu, 2014).

Data kependudukan dan Keluarga Berencana Nasional (BKKBN) menunjukkan bahwa pada tahun 2013 ada 8.500.247 PUS (Pasangan Usia Subur) yang merupakan peserta $\mathrm{KB}$ baru dan hampir separuhnya $(48,56 \%)$ menggunakan metode Kontrasepsi Suntikan (Pusat Data dan Informai Kementerian Kesehatan RI, 2013).

Keluarga Berencana merupakan salah satu pelayanan kesehatan preventif yang paling dasar dan utama bagi wanita. Peningkatan dan perluasan pelayanan Keluarga Berencana merupakan salah satu usaha untuk menunjukkan angka kesakitan dan kematian ibu yang sedemikian tinggi akibat kehamilan yang dialami oleh wanita.

Dalam memilih suatu metode alat kontrasepsi wanita harus menimbang berbagai faktor termasuk status kesehatan, efek samping suatu metode konsekuensi terhadap kehamilan dan yang tidak diinginkan dan norma budaya mengenai anak (Gungde, 2008 Dalam Henny 2009).

Sampai saat ini belum ada satu cara kontrasepsi yang ideal. Kontrasepsi yang ideal memiliki ciri-ciri yaitu : berdaya guna, aman, murah, estetik, mudah didapatkan, tidak memerlukan motivasi yang terus menerus efek samping minimal.

Adapun syarat-syarat alat kontrasepsi yaitu; aman pemakaiannya dan dipercaya, tidak ada efek samping yang merugikan dan kerjanya dapat diatur menurut keinginan. Cara penggunaannya sederhana atau tidak rumit, harga murah dan dapat dijangkau oleh masyarakat dapat diterima oleh pasangan suami istri (Proverawati, A, 2010).
Peserta program KB secara nasional tahun 2010 mencapai 32 juta akseptor yang terdiri dari sebanyak 28 juta akseptor dan 4 juta akseptor baru (BKKBN, 2010 dalam Ardyguna, 2012).

Berdasarkan hasil penelitian Enny Juniaty Sutorejo (Surabaya, 2009) terdapat jumlah akseptor kontrasepsi pada bulan januari sampai Desember sebanyak 3054 akseptor dengan data sebagai berikut : kontrasepsi suntik $85,8 \%$, kontrasepsi pil 13,8\%, kontrasepsi IUD $0,2 \%$, kontrasepsi implant $0,06 \%$.

Ada hubungan signifikan antara Tingkat Pengetahuan Ibu tentang kontrasepsi Suntik dengan sikap dalam Memilih KB suntik 3 Bulanan di Desa Besole, Kecamatan Bayan, Kabupaten Purworejo dengan koefisien korelasi Kendall Tau sebesar 0,536 (Approx sig 0,000< 0,05 dan $\mathrm{Z}$ hitung 3,999 > Z tabel 1,96) dengan tingkat kekuatan hubungan sedang. Berarti semakin tinggi tingkat pengetahuan tentang $\mathrm{KB}$ suntik akan memiliki kecenderungan sikap yang semakin mendukung dalam pemilihan KB suntik 3 bulanan (Dwi Mardiantari, 2011).

Pemilihan alat kontrasepsi dapat dipengaruhi oleh beberapa karakteristik akseptor kontrasepsi seperti pengetahuan, jarak pelayanan kesehatan, biaya kontrasepsi, dan dukungan suami. Karakteristik tersebut sejalan dengan hasil penelitian Mayasari (2008).

Berdasarkan penelitian Mutiara Puspa (2014), maka dapat diperoleh adanya hubungan antara pengetahuan ibu tentang kontrasepsi dengan pemilihan penggunaan kontrasepsi di Desa Pisang Kecamatan Patianrowo Kabupaten Nganjuk Tahun 2014.

Tingginya tingkat penggunaan alat kontrasepsi oleh pasangan suami istri Indonesia sebagian besar karena keberhasilan Program Keluarga Berencana (KB) pemerintah . berkat tanggung jawab yang kuat dan bantuan pemerintah untuk menurunkan pertumbuhan jumlah penduduk yang menghawatirkan ini, maka pada tahun 1969 terbentuklah Badan Koordinasi Keluarga Berencana Nasional (BKKBN) dan Program Keluarga Berencana Nasional sebagai sebagian dari repelita pertama.

Walaupun program ini pada awalnya memusatkan perhatian di Jawa dan Bali, secara bertahap mencakup provinsi-provinsi di luar Jawa, Bali, Madura (Koes Irianto hal 13,2012 dalam Nani Anggraini 2013).

Menurut Hartanto (2003, dalam Nina Siti 2013) salah satu efek samping dari metode suntikan adalah adanya penambahan berat badan. Umumnya pertambahan berat badan tidak terlalu besar, bervariasi antara kurang dari satu kilogram sampai lima kilogram dalam tahun pertama. Penyebab pertambahan berat badan tidak jelas. Tampaknya terjadi karena bertambahnya lemak tubuh, dan bukan karena retensi cairan tubuh. Hipotesa para ahli: DMPA (Depot medroxy progesterone acetate) merangsang pusat pengendali nafsu makan di hipotalamus yang menyebabkan akseptor makan lebih banyak dari pada biasanya.

Wanita yang menggunakan kontrasepsi Depot Medroxy Progesterone Acetate (DMPA) atau dikenal dengan Kontrasepsi Suntik tiga bulan, rata-rata mengalami peningkatan berat badan sebanyak 11 pon atau 5,5 kilogram, dan mengalami peningkatan lemak tubuh 
sebanyak 3,4\% dalam waktu tiga tahun pemakaian, berdasarkan penelitian yang dilakukan oleh University of Texas Medical Branch (UTMB) (Mansjoer, 2003 dalam Henny 2009).

Sedangkan pada kontrasepsi suntik bulanan efek samping terhadap berat badan sangatlah ringan, umumnya pertambahan berat badan sedikit (Hartanto, 2003 dalam Nina Siti 2013).

Dari data yang diperoleh di RB. Sitiana Barus jumlah pemakai Kontrasepsi Suntik 3 bulan dari bulan Januari 2014 sampai bulan Desember 2014 berjumlah 311 orang dan jumlah pemakai kontrasepsi suntik yang berpindah dari 3 bulan ke 1 bulan dari bulan Januari 2014 sampai Desember 2014 berjumlah 105 orang. Hasil survei pendahuluan dari wawancara langsung terhadap ibu yang memakai Kontrasepsi Suntik terdapat 5 orang, yang berpindah dari kontrasepsi suntik 3 bulan menjadi kontrasepsi 1 bulan, ibu mempunyai alasan tidak mensturasi dan menjadi gemuk (penambahan berat badan) jika menggunakan kontrasepsi suntik 3 bulan dan si ibu ingin berpindah sementara ke kontrasepsi suntik 1 bulan. Dengan demikian peneliti tertarik untuk mengetahui Pengetahuan Dan Sikap Ibu Tentang Kontrasepsi Suntik Di RB. Sitiana Barus Desa Namo Bintang Kec. Pancur Batu Tahun 2015.

\section{METODOLOGI PENELITIAN}

Jenis penelitian yang digunakan adalah desain penelitian Cross Sectional yaitu suatu metode yang merupakan rancangan penelitian yang melakukan pengukuran atau pengamatan pada saat bersamaan (sekali waktu) dengan jenis penelitian deskriptif (Notoatmodjo, 2010).

\section{HASIL PENELITIAN}

Diuraikan hasil penelitian dan pembahasan mengenai pengetahuan dan sikap ibu tentang kontrasepsi Suntik di RB. Sitiana Barus Desa Namo Bintang Kec. Pancur Batu Tahun 2015 pada bulan Juli-Agustus 2015 dengan responden sebanyak 31 orang.

\section{ANALISA DATA}

Tabel 1. Distribusi Frekuensi Pengetahuan dan Sikap Ibu tentang Kontrasepsi Suntik berdasarkan Pengetahuan di RB. Sitiana Barus Desa Namo Bintang Kec. Pancur Batu Tahun 2015

\begin{tabular}{|c|l|c|c|}
\hline No & Pengetahuan & Frekuensi & Persentase \\
\hline 1 & Baik & 6 & $19,4 \%$ \\
\hline 2 & Cukup & 13 & $41,9 \%$ \\
\hline 3 & kurang & 12 & $38,7 \%$ \\
\hline \multicolumn{2}{|c|}{ Total } & $\mathbf{3 1}$ & $\mathbf{1 0 0 \%}$ \\
\hline
\end{tabular}

Berdasarkan tabel 4.1 diketahui bahwa ibu yang menggunakan kontrasepsi suntik pengetahuan cukup 13 orang (41,9\%), pengetahuan kurang 12 orang 38,7\%), dan pengetahuan baik 6 orang $(19,4 \%)$.
Tabel 2. Distribusi Frekuensi Pengetahuan dan Sikap Ibu tentang Kontrasepsi Suntik berdasarkan Sikap di RB. Sitiana Barus Desa Namo Bintang Kec. Pancur Batu Tahun 2015

\begin{tabular}{|l|l|l|c|}
\hline No & \multicolumn{1}{|c|}{ Sikap } & Frekuensi & Persentase \\
\hline 1 & Positif & 30 & $96,8 \%$ \\
\hline 2 & Negative & 1 & $3,2 \%$ \\
\hline \multicolumn{2}{|c|}{ Total } & $\mathbf{3 1}$ & $\mathbf{1 0 0 \%}$ \\
\hline
\end{tabular}

Berdasarkan tabel 4.2 diketahui bahwa ibu yang menggunakan kontrasepsi suntik berdasarkan Sikap positif 30 orang $(96,8 \%)$ dan sikap Negatif 1 orang $(3,2 \%)$.

\section{PEMBAHASAN}

Setelah dilakukan penelitian tentang Pengetahuan dan Sikap Ibu Tentang Kontrasepsi Suntik di RB. Sitiana Barus Desa Namo Bintang Kec. Pancur Batu Tahun 2015 akan dibahas sebagai berikut.

\section{Pengetahuan}

Penelitian ini dilakukan terhadap 31 responden didapat hasil distribusi frekuensi pengetahuan ibu tentang kontrasepsi suntik di RB. Sitiana Barus Desa Namo Bintang Kec. Pancur Batu terdapat lebih banyak ibu yang perpengetahuan cukup yaitu 13 orang $(41,9 \%)$, kemudian yang berpengetahuan kurang sebanyak 12 orang $(38,7 \%)$, dan ibu yang berpengetahuan baik yaitu 6 orang $(19,4 \%)$. Sesuai peneliti temukan di lapangan dimana responden yang berpengetahuan baik adalah ibu-ibu yang memahami dan mengerti tentang kontrasepsi suntik dikarenakan ibu-ibu tersebut mau mencari dan mendengarkan setiap informasi kesehatan yang diberikan oleh petugas kesehatan, namun masih banyak yang kurang mengerti dan memahami tentang kontrasepsi suntik, begitu pula disaat pengisian kuesioner, responden selalu bertanya tentang kuesioner yang dibagikan kepada responden tersebut maka didapatlah hasil yang paling banyak perpengetahuan cukup.

Pengetahuan merupakan hasil tahu manusia yang terjadi setelah seseorang melakukan penginderaan terhadap suatu objek tertentu (Notoadmo djo, 2007) Di lihat dari penelitian Dwi Mardiantari, 2011 dengan penelitian Hubungan Antara Tingkat Pengetahuan Ibu Tentang KB Suntik Dengan Sikap Dalam Memilih KB Suntik Di Desa Besole Kec. Bayan Kab. Purworejo. Dapat diketahui responden terbanyak memiliki pengetahuan tentang kontrasepsi suntik kurang yaitu 19 orang $(63,3 \%)$ dan paling sedikit memiliki pengetahuan tentang kontrasepsi suntik baik sebanyak 4 orang $(13,3 \%)$ dengan jumlah responden 30 orang. Maka, jika teori dikaitkan dengan hasil penelitian tidak ditemukan kesenjangan.

\section{Sikap}

Setelah dilakukan penelitian terhadap 31 responden didapat hasil distribusi frekuensi sikap ibu tentang kontrasepsi suntik di RB. Sitiana Barus Desa 
Namo Bintang Kec. Pancur Batu terdapat ibu yang mempunyai sikap positif sebanyak 30 orang $(96,8 \%)$, dan yang bersikap negatif hanya 1 orang $(3,2 \%)$.

Perbedaan yang jauh antara sikap positif dan negatif yang ditemukan pada data di atas sesuai dengan yang ditemukan peneliti di lapangan, dimana pada saat kuesioner dibagikan kepada responden, responden kurang memahami dan bertanya kepada peneliti, penelitipun berusaha menjelaskan satu persatu dari kuesioner yang peneliti bagikan, ini mungkin berpengaruh dalam sikap responden dan emosional responden juga mempengaruhi sikap yang dimilikinya.

Sikap merupakan pandangan atau perasan yang disertai kecenderungan untuk bertindak terhadap obyek tertentu. Sikap bisa bersifat positif dan negatif dalam hubungannya dalam hubungannya dengan objek psikologis (Sarwono, 2003).

Dari hasil penelitian Nani Anggaraini, 2013. Hubungan Pengetahuan dan Sikap Pasangan Usia Subur Terhadap Pemilihan Kontrasepsi Modren di Desa Suka Karya Kec. Simeulue Timur Kab. Simeulue. Penggunaan kontrasepsi oleh PUS ditinjau dari sikap positif sebanyak 15 responden dan sikap negatif sebanyak 6 responden. Maka teori dikaitkan dengan hasil penelitian tidak ada kesenjangan.

\section{KESIMPULAN}

Berdasarkan hasil analisa dan pembahasan dapat diambil kesimpulan mengenai Pengetahuan Dan Sikap Ibu Tentang Kontrasepsi Suntik Di RB. Sitiana Barus Desa Namo Bintang Kec. Pancur Batu Tahun 2015. Maka ditarik kesimpulan sebagai berikut :

1. Dari semua data yang diperoleh maka hasil penelitian berdasarkan pengetahuan ibu tentang kontrasepsi suntik menunjukkan dari 31 responden dengan mayoritas memiliki pengetahuan cukup 13 orang (41,9\%). Hal ini dapat dilihat dari data yang diperoleh dari kuesioner.

2. Dari semua data yang diperoleh maka hasil penelitian berdasarkan sikap ibu tentang kontrasepsi suntik menunjukkan dari 31 responden dengan mayoritas memiliki Sikap positif 30 orang $(96,8 \%)$. Hal ini dapat dilihat dari data yang diperoleh dari kuesioner.

\section{SARAN}

1. Bagi pemilik RB

Kepada petugas kesehatan khususnya kepada pemilik RB. Sitiana Barus dapat meningkatkan SD dan memberikan penyuluhan ataupun pendidikan dan pelayanan kesehatan dan mensosialisasikan dan meningkattkan kesadaran bagi ibu-ibu (PUS) tentang kontrasepsi suntik.

2. Bagi Responden

Kepada ibu-ibu agar lebih aktif dalam memperkaya ilmu pengetahuan dan kesehatan dengan banyak membaca atau mendengar dari media elektronok ataupun berkonsultasi pada petugas kesehatan tentang kontrasepsi suntik agar lebih mampu mengetahui, memamahi, mengaplikasikan, menyimpulkan, menilai tentang kontrasepsi suntik.

3. Bagi Peneliti

Kepada peneliti dapat memberikan pelayanan yang terbaik untuk pasien.

\section{DAFTAR PUSTAKA}

Aga, Bramantia, 2013. Gambaran Pengetahuan Ibu Usia Subur (15 - 49 tahun) Tentang Alat Kontrasepsi Dalam Rahim di Kelurahan Cisaranten Waten Kota Bandung.

Ariwahyudi. Web id/jumlah-pendudukindonesia 2015.

Ardyguna, 2012. Faktor-faktor yang Mempengaruhi Ibu Dalam Pengambilan Keputusan Menggunakan Kontrasepsi Suntik di Wilayah Kerja Puskesmas Banjarnegara I Kabupaten Banjarnegara.

BKKBN, 2011. Buku Panduan Praktis Pelayanan Kontrasepsi edisi 4. Jakarta Bina Pustaka Sarwono Prawirohardjo. Data Kecamatan Pancur batu 2014.

Depkes RI, 2013. Pusat Data Informasi

Web site http://www.kemkes.go.id

Dewi M dan A. Wawan, 2011. Teori \& Pengukuran Pengetahuan, Sikap, Dan Perilaku Manusia. Yogyakarta : Nuha Medika

Dwi Mardiantara, 2011. Hubungan Antara Tingkat Pengetahuan Ibu Tentang KB Suntik Dengan Sikap Dalam Memilih KB Suntik 3 Bulanan Di Desa Besole Kec. Bayan Kab. Purworejo.

Henny, 2009 Hubungan pengetahuan dan sikap ibu pus akseptor kontrasepsi non hormonal tentang kontrsepsi hormonal di desa telaga sari tanjung morawa.

Inggriany Theresia Rumende,2015. Evaluasi Penggunaan Kontrasepsi Suntik Pada Pasangan Usia Subur (PUS) Di Kelurahan Walian I Tomohon.

Mayasari, 2008. Hubungan Faktor Sosial Budaya Dengan Keikut Sertaan KB Di Puskesmas Mergangsan Kota Yogyakarta.

Mutiara Puspa, 2014. Hubungan Pengetahuan Ibu Tentang Kontrasepsi Dengan Pemilihan Penggunaan Kontrasepsi.

Mulyani Nina Siti, dkk, 2013. Buku Keluarga Berencana Dan Alat Kontrasepsi. Yogyakarta : Nuha Medika

Nani Anggaraini, 2013. Hubungan Pengetahuan Dan Sikap Pasangan Usia Subur Terhadap Pemilihan Kontrasepsi ModrenDi Desa Suka Karyya Kec. Simeulue Timur Kab. Simeulue.

Nella destari, 2014 Faktor-faktor penyebab PUS tidak memilih IUD sebagai alat kontrasepsi di BPS IKA Dusun IX Desa Bandar Setia Kec,percut sei tuan kab. deli serdang. Nelladestari.blogspot.com

Proverawati, dkk, 2010 Kapita Selekta ASI dan Menyusui. Yogyakarta : Nuha Medika. 